\title{
First Phylogenetic Treatment of Apple Cucumber (Family Cucurbitaceae) from Indonesia Utilizing DNA Variation of Internal Transcibed Spacer Region
}

\author{
Topik Hidayat ${ }^{1 *}$, Nurcahyo Widyodaru Saputro², Miftakhul Bakhrir Rozaq Khamid², Fawzy Muhammad Bayfurqon² \\ ${ }^{1}$ Department of Biology Education, Universitas Pendidikan Indonesia, Bandung, Indonesia \\ ${ }^{2}$ Department of Agrotechnology, Singaperbangsa University Karawang, Karawang, Indonesia
}

\section{ARTICLE INFO}

Article history:

Received November 20, 2019

Received in revised form October 5, 2020

Accepted October 9, 2020

KEYWORDS:

Apple Cucumber,

Cucurbitaceae,

ITS region,

phylogeny

\begin{abstract}
Cucurbitaceae is one of the largest family in Angiosperm in which the most member of this family is important fruit crops in Indonesia such as Cucumber, Melon, Watermelon, and Apple Cucumber. In particular, Apple Cucumber, currently attracts attention to many researchers due to its phylogeneticand taxonomic problem. In term of its appearance, the fruit looks like an apple but the taste is melon. The purpose of this study was to elucidatephylogenetic relationship between Apple Cucumber and other species of Cucurbitaceae based on variation of DNA sequences derived from internal transcribed spacer (ITS) region. As many as six individuals of Apple Cucumber collected from Karawang, Jember, and Aceh were examined. The ITS sequences of some species of family Cucurbitaceae were retrieved from GenBank, and put them in the analysis. Phylogenetic analysis based on parsimony method with using Begoniaas outgroup reveals that Apple Cucumber are nested in the same clade as Melon (Cucumis melo) with high bootstrap value $(\mathbf{1 0 0 \%})$, suggesting that Apple Cucumber is under the same species as Melon. However, on the basis of morphological characters of fruit, apple cucumber is different with that of Melon. This considerably first phylogenetics treatment provides fundamental knowledge for establishing a subspecies of Melon.
\end{abstract}

\section{Introduction}

Cucurbitaceae is huge and diverse family in angiosperm, comprising about 96 genera with approximately 1,000 species (Renner and Schaefer 2017). The most member of this family plays important role as the main fruit crop commodities in Indonesia. Cucumis is among the most popular genus in the family since many species of Cucumis are favored by the community due to their rich in sources of vitamins and minerals, such as $C$. sativus (Cucumber) and C. melo (Melon). Cucumber and Melon are two common fruit crops that has been known worldwide.

For a long time peoples in Indonesia have been surprised by the present of "new comer" tropical fruit, namely Apple Cucumber, especially in Aceh, and recently this plant has spread in Karawang, Jember and other regions. Apple cucumber is assumed to

\footnotetext{
* Corresponding Author

E-mail Address: topikhidayat@upi.edu
}

be a natural hybrid between Cucumber and Melon (no previous report about this), and is likely to have originated in China (Sebastian et al. 2010; Zhang et al. 2012). Its appearance looks like an apple but the taste is melon, leading to phylogenetic (the origin and relationships) and taxonomic (the naming) problems of this plant in the family Cucurbitaceae. However, so far no studies have been conducted to address these problems.

This present study was aimed at elucidating phylogenetic relationships between Apple Cucumber and other species of Cucurbitaceae using variation of DNA sequences of internal transcribed spacer (ITS) regions of nuclear ribosomal DNA, and eventually giving taxonomic identity for Apple Cucumber. The ITS regions used here is in part due to its small size (less than $700 \mathrm{bp}$ ) and tandem repeat array (Baldwin et al. 1995), so that easy to handle. The ITS regions have been used successfully for addressing phylogenetic problem in many family of plants (e.g. Suetsugu et al. 2018). 


\section{Materials and Methods}

\subsection{Plant Materials}

In total, six individuals of apple cucumber distributed in Karawang, Jember, and Aceh were analyzed with a single genus Begonia were used as outgroup. The ITS sequences of the outgroup along with some species of family Cucurbitaceae were retrieved from GenBank (www.ncbi.nlm.nih.gov). Table 1 describes detail information about plant materials and ITS sequences used in this study.

\subsection{Amplification and Sequencing}

Total DNA was extracted from fresh materials using a GeneJET Plant Genomic Purification Mini Kit (Thermo Scientific, USA) following manufacturer's instructions. Primer pairs ITS-5 (5'-TAGAGGAAGGAGAAGTCGTAACAA-3') as forward and ITS-4 (5'-CCCGCCTGACCTGGGGTCGC-3') as reverse primer following Hidayat et al. (2008) were used (see Figure 1). The PCR profile consisted of an initial 2 min premelt at $95^{\circ} \mathrm{C}$ and 35 cycles of $30 \mathrm{~s}$ at $95^{\circ} \mathrm{C}$ (denaturation), $2 \mathrm{~min}$ at $57^{\circ} \mathrm{C}$ (annealing), and 2 min at $72^{\circ} \mathrm{C}$ (extension), followed by a final 10 min extension at $72^{\circ} \mathrm{C}$. The PCR products were sent to Macrogen, South Korea for DNA sequencing.

\subsection{Phylogenetic Analysis}

DNA sequences of the ITS region obtained were aligned with ClustalX(Thompson etal. 1997) and were adjusted manually. Phylogenetic tree reconstruction based on parsimony method was performed using PAUP* version 4.0b10 (Swofford 1998). Insertion and deletion were treated as missing data. All characters were equally weighted and unordered (Fitch 1971). The evaluation the internal support of clades was conducted by bootstrap analysis (Felsenstein 1985) utilizing 1,000 replicates. The number of steps, consistency indices $(\mathrm{CI})$, and retention indices (RI) were calculated using the TREE SCORE command in PAUP*.

\subsection{Morphological Observation}

Diagnostic morphological characters were analysed according to The International Plant Genetic Resources Institute (IPGRI 2003) in order to provide more evidences.

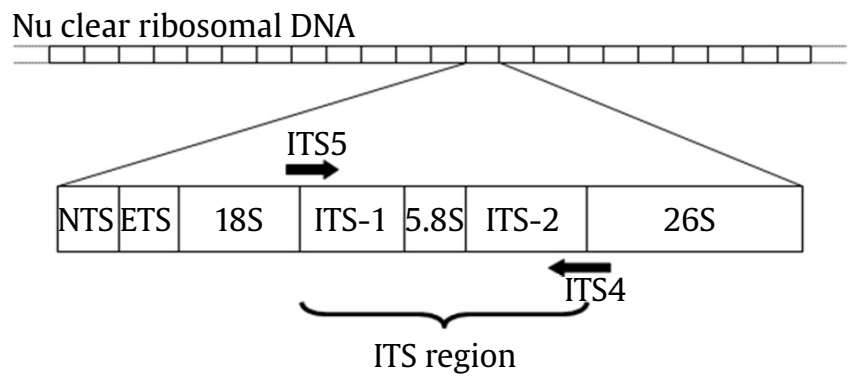

Figure 1. Position of primers applied in this study

Table 1. Plant materials examined in this study

\begin{tabular}{|c|c|c|c|c|}
\hline Plant (local name) & Species & Code & Location & Accession number \\
\hline Apple cucumber & & B & Karawang & \\
\hline Apple cucumber & & $\mathrm{D}$ & Jember & \\
\hline Apple cucumber & & E & Jember & \\
\hline Apple cucumber & & $\mathrm{F}$ & Jember & \\
\hline Apple cucumber & & G & Jember & \\
\hline Apple cucumber & & $\mathrm{J}$ & Aceh & \\
\hline Melon & Cucumis melo & & & HQ201970 \\
\hline Cucumber & Cucumis sativus & & & AY833602 \\
\hline Cucumber & Cucumis sativus & $\mathrm{H} 2$ & & \\
\hline White gourd & Benincasa hispida & & & JX073074 \\
\hline Watermelon & Citrulus lanatus & I & & \\
\hline Mouse melon & Melothria scabra & & & GU799500 \\
\hline Pumpkin & Cucurbita moschata & & & FJ915110 \\
\hline Chayote & Sechium edule & & & AM981178 \\
\hline Chinese okra & Luffa acutangula & & & КС329521 \\
\hline Bitter gourd & Momordica charantia & & & HQ201988 \\
\hline Serpent gourd & Trichosanthes cucumerina & & & GQ240882 \\
\hline Begonia* & Begonia sp. & & & HQ729030 \\
\hline
\end{tabular}




\section{Results}

The alignment process resulted in 650 characters after adjusment by eye, of which 283 (42\%) were constant, 181 (28\%) were uninformative, and 186 (30\%) were parsimony informative. Parsimony analysis produced a single tree (Figure 2) with 727 steps, $\mathrm{CI}$ and $\mathrm{RI}$ value are 0.714 and 0.660 , respectively.

The tree (Figure 2) confirms that Apple Cucumber is the hybridization result between Melon and Cucumber. Moreover, the tree places Apple Cucumber examined in the same clade with Melon (C. melo) with strong bootstrap value (100\%), suggesting they are belong to the same species of Melon, C. melo. This result has addressed the puzzle of what species Apple Cucumber belongs to.

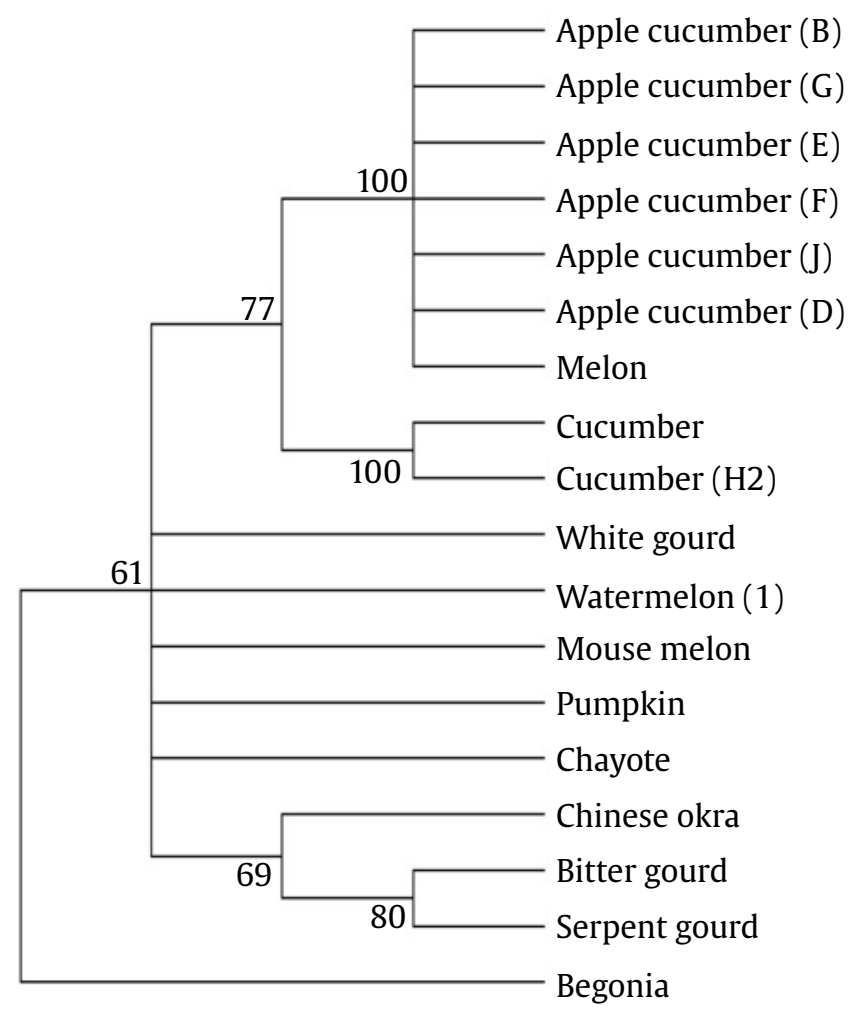

Figure 2. Phylogenetic tree of apple cucumber based on the ITS region. Only bootstrap values of more than 50 is displayed on the branch

\section{Discussion}

In many phylogenetic studies, using only a single data set, even molecular data, might not elucidate phylogenetic relationships and taxonomic identity of the organisms examined (e.g. Doyle 2013; Bagheri et al. 2016). This is because every single data represents different evolutionary history (Lang et al. 1999) and may lead to the wrong conclusions about the relationships (Qi et al. 2013). Therefore, the use of multiple data set and their combination could provide more reliable results. On the other hand, despite its superiority in molecular phylogenetic studies, the ITS region has some disadvantages especially related with problem in failure of concerted evolution. Every ITS unit (Figure 2) along a hundred or thousand copies that arrange nrDNA (nuclear ribosomal DNA) evolves independently, and this is subjected to paralogous (Baldwin et al. 1995).

Regarding this situation, DNA sequences of the ITS region utilised in this present study has been accompanied by morphological characters to provide the most informative tree. Thus, 141 morphocharacters were added to molecular data, and were resulted in more robust phylogenetic tree (Figure 3) than previous one (Figure 2). All samples of Apple Cucumber form their own clade and become a sister group of Melon. It is meaning that Apple Cucumber and Melon are different, although on the basis of DNA variation, they differ only in three locations throughout the ITS sequences (Figure 4). From this combined analysis and more detailed morphological observation, we identified that as many as 21 characters are informative (Table 2) to distinct Apple Cucumber from Melon.

Another things should be pointed out here is lack support of morphological data to the ITS data. We identified nucleotides difference of ITS sequences between Apple Cucumber and Melon only in three locations (Figure 4), whereas morphologically (mostly fruit) they are very different (Table 2 ). In eukaryotes, this situation is not rare, without exception in plant 


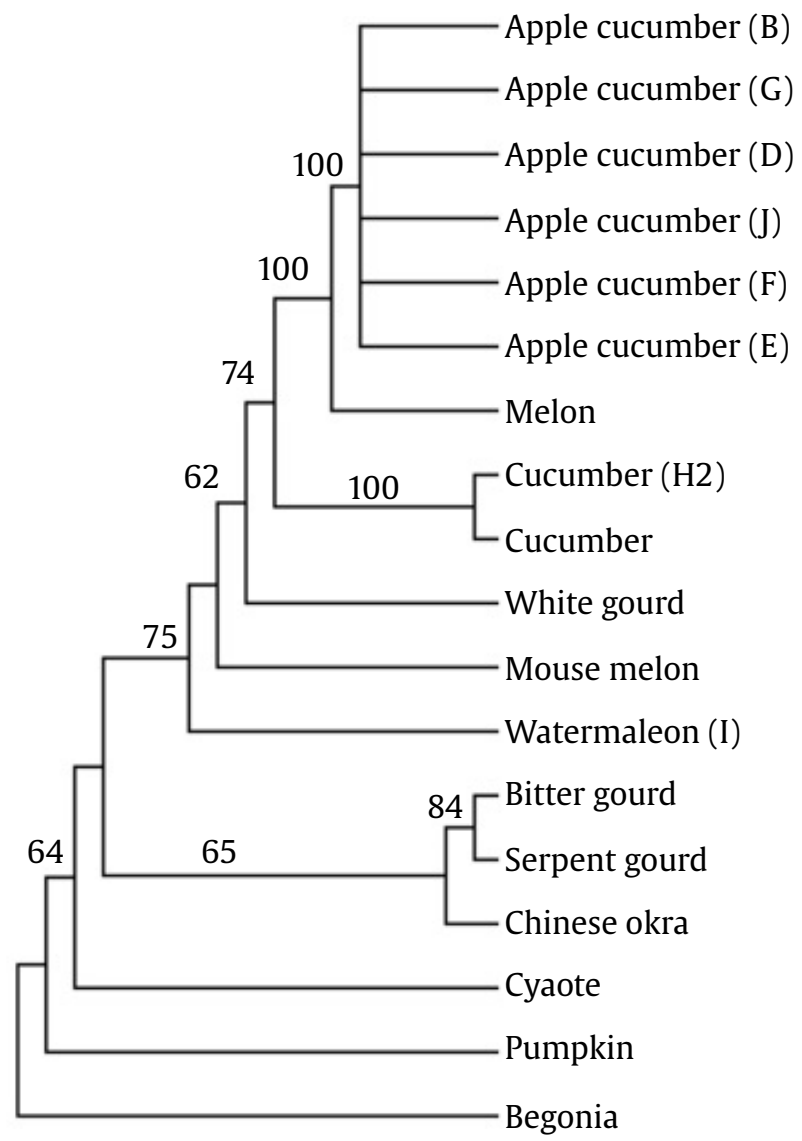

Figure 3. A single phylogenetic tree constructed by combining molecular and morphological data (748 steps of length, 0.722 of $\mathrm{CI}$, and 0.709 of $\mathrm{RI})$ (e.g. Stepanovic et al. 2016). Epigenetics phenomenon in plant is remarkable (Pikaard and Scheid 2014). Less variation of DNA sequences do not always bring to less variation of morphology, but this often causes a wide phenotypic diversity (Carvalho et al. 2017).

The taste of Apple Cucumber is very much like Melon, although the shape of fruit looks like an apple. This is in accordance with position of Apple Cucumber and Melon in the tree (Figure 3). Apple Cucumber is considered to be a subspecies of Melon in Indonesia as suggested by this study. Not only this study, a new subspecies through phylogenetic analysis has been proposed by many researchers in angiosperm group (Zeng et al. 2014) such as in Dasyphyllum (Ferreira et al. 2019). On the basis of detailed quantitative and qualitative morpho-agronomic characters (141 characters), these two plants are different (Saputro et al. 2020).

In the end, this study clearly shows that Apple Cucumber is more closely related with Melon (C. melo) rather than Cucumber (C. sativus). This suggests that scientific name of Apple Cucumber would be $C$. melo. In addition, we identified 21 key characters (mostly character of fruit) that can be used to distinguish Apple Cucumber from that of Melon, providing a fundamental knowledge for establishing a subspecies of Melon. Further phylogenetic studies, however, with extensive sampling and utilizing more

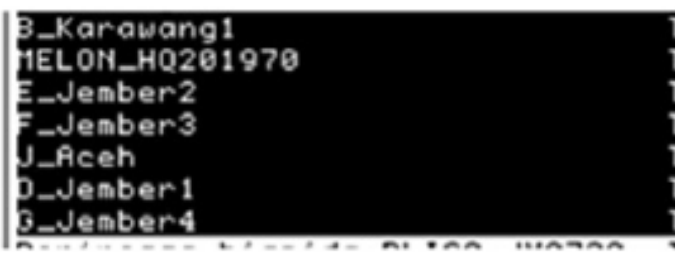

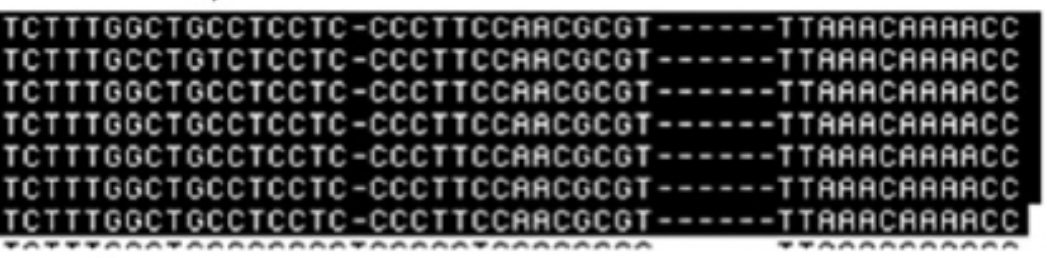

\section{凤}

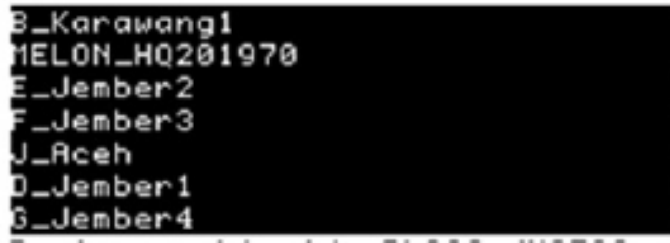

TRCTR - -ACARCGACTCTCGGCARCGGATATCTCGGCTCTCGCATCGRT

TACT =--ACARCGACTCTCGGCAACGGATATCTCGGCTCTCGCATCGAT

TACTA - -ACAACGACTCTCGGCAACGGATATCTCGGCTCTCGCATCGAT

TACTA - -ACAACGACTCTCGGCAACGGATATCTCGGCTCTCGCATCGAT

TACTA--ACARCGACTCTCGGCARCGGATATCTCGGCTCTCGCATCGAT

TACTA - -ACARCGACTCTCGGCAACGGATATCTCGGCTCTCGCATCGAT

TACTA - -ACAACGACTCTCGGCAACGGATATCTCGGCTCTCGCATCGAT

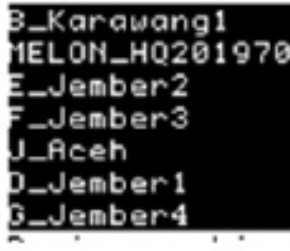

\section{$\sqrt{2}$}

CTCCCGTACGCA-CCGTCGTGCGGATGGCTTARATTCGAGTCCTCGATGC CTCCCGTACGCA - TCGTCGTGCGGATGGCT TAAAT TCGAGTCCTCGATGC CTCCCGTACGCA-CCOTCGTGCGGATGGCT TAAATTCGAGTCCTCGATGC CTCCCGTACGCA-CCGTCGTGCGGATGGCTTAAATTCGAGTCCTCGATGC CTCCCGTACGCA-CCGTCGTGCGGATGGCT TAAAT TCGAGTCCTCGATGC CTCCCGTACGCA-CCGTCGTGCGGATGGCT TARAT TCGAGTCCTCGATGC CTCCCGTACGCA-CCGTCGTGCGGATGGCT TAAAT TCGAGTCCTCGATGC

Figure 4. Nucleotide differences between Apple cucumber and melon in three locations (arrow) throughout the ITS region (650 nucleotides) 
Table 2. Diagnostic characters between Apple Cucumber and Melon

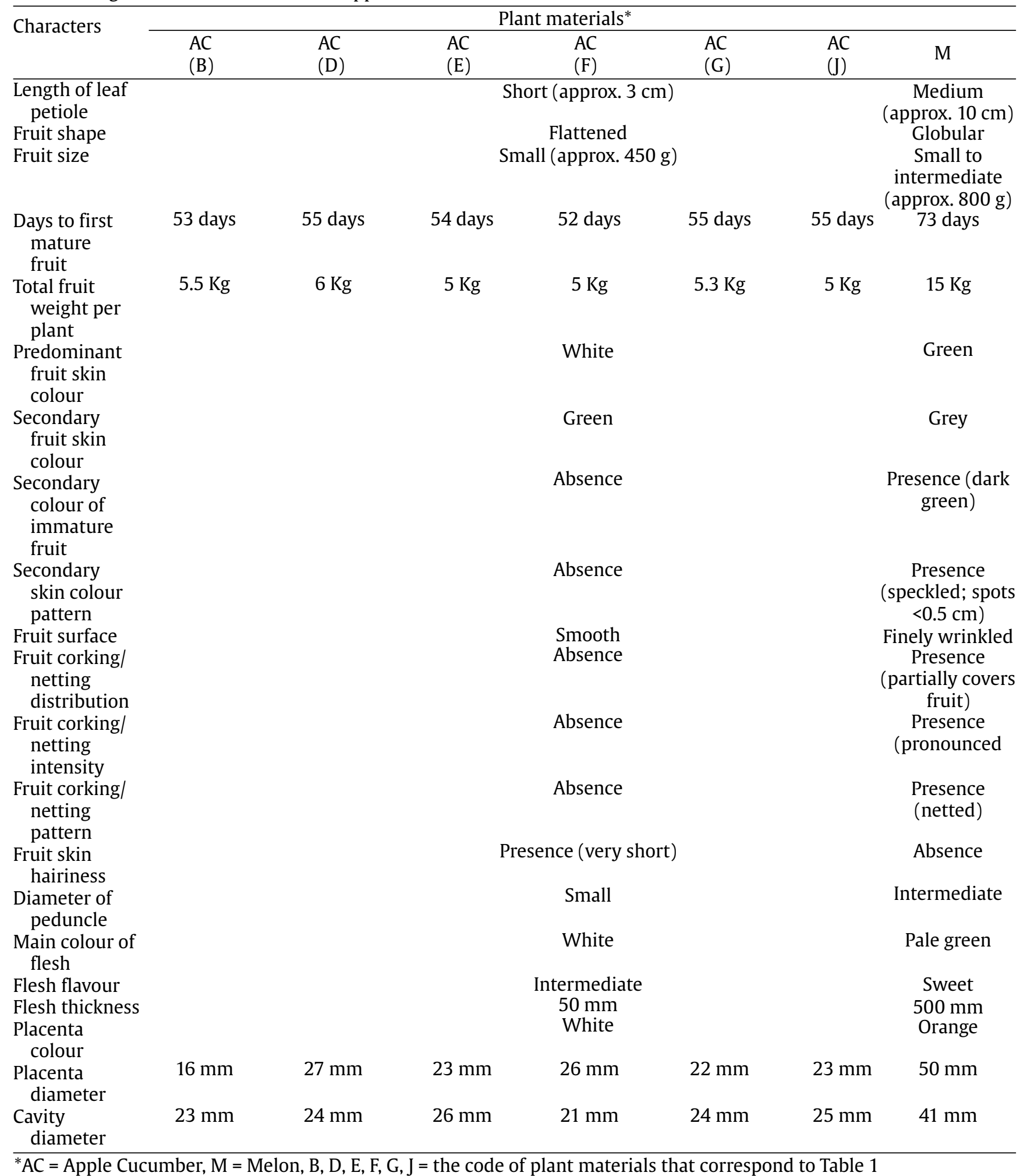


genetic markers are desirable to carry out in the future in order to provide more plausible evidence for Apple Cucumber in phylogenetic and taxonomic context.

\section{Acknowledgements}

The authors acknowledge a research funding by Indonesia Ministry of Research Technology and Higher Education (No. 092/SP2H/DRPM/2018). We also thank Anggi Meinawan Insanie, S.Si. for her skillful in laboratory work.

\section{References}

Baldwin BG et al. 1995. The ITS region of nuclear ribosomal DNA: a valuable source of evidence on angiosperm phylogeny. Annals of The Missouri Bot Gard 82:247277.

Bagheri A et al. 2016. Molecular phylogeny and morphological analysis support a new species and new synonymy in Iranian Astragalus (Leguminosae). PLoSONE 11:e0149726.

Carvalho $\mathrm{N}$ et al. 2017. Analysis of genetic variability of commercial melon cultivars using SSR molecular markers. Genetic Molecular Research 16:gmr16039739.

Doyle JA. 2013. Phylogenetic analyses and morphological innovations in land plants. Annual Plant Reviews 45: $1-50$.

Felsenstein J 1985. Confidence limit on phylogenies: an approach using the Bootstrap. Evolution 39:783-791.

Ferreira PL et al. 2019. Phylogeny and circumscription of Dasyphyllum (Asteraceae) based on molecular data with the recognition of a new genus, Aschidasyphyllum. PeerJ 6475:1-19.

Fitch WM 1971. Toward defining the course of evolution: minimum change for a specific tree topology. Systematic Zoology 20:406-416.

Hidayat T et al. 2008. Analisis filogenetik molekuler pada Phyllanthus niruri L. (Euphorbiaceae ) menggunakan urutan basa DNA daerah internal transcribed spacer ( ITS). Jurnal Matematika Dan Sains 13:16-21.
[IPGRI] International Plant Genetic Resources Institute. 2003. Descriptors for melon (Cucumis melo L.). IPGRI: Rome Italy.

Lang BF et al. 1999. Mitochondrial genome evolution and the origin of eukaryotes. Annual Reviews Genetics 33:351-397.

Pikaard CS, Scheid OM. 2014. Epigenetic regulation in plants. Cold Spring Harbor Perspective Biology 6:a019315.

Qi J et al. 2013. A genomic variation map provides insights into the genetic basis of cucumber domestication and diversity. Nature Genetic 45:1510-1515.

Renner SS, Schaefer H. 2017. Phylogeny and evolution of the Cucurbitaceae. Pl Gen Genom 20:13-23.

Saputro NW et al. 2020. Evaluation of morpho-agronomic characterization Apple Cucumber: a new variety of melon from Indonesia. IOP Conf Ser: Earth Environ Sci 457:012061. DOI:10.1088/1755-1315/457/1/012061

Sebastian P et al. 2010. Cucumber (Cucumis sativus) and melon (C. melo) have numerous wild relatives in Asia and Australia, and the sister species of melon is from Australia. Proc of the Nat Acad Sc 107:14269-14273.

Suetsugu Ket al.2018. The taxonomic identity of three varieties of Lecanorchis nigricans (Vanilleae, Vanilloideae, Orchidaceae) in Japan. PhytoKeys 92:17-35.

Stepanovic S et al. 2016. Morphology versus DNA barcoding: two sides of the same coin: a case study of Ceutorhynchus erysimi and C. contractus identification. Insect Science 23:638-648.

Swofford DL 1998. PAUP*4.0b10. Phylogenetic Analysis Using Parsimony ( ${ }^{*}$ and other Methods), Version 4. Sunderland: Sinauer Associates.

Thompson ID et al. 1997. The clustalX-windows interface: flexible strategies for multiple alignment through sequence alignment aided by quality analysis tools. Nucleid Acids Research 25:4876-4882.

Zhang C et al. 2012. Evaluation of morphological and molecular diversity among South Asian germplasms of Cucumis sativus and Cucumis melo. ISRN Agronomy $12: 1-11$.

Zeng L et al. 2014. Resolution of deep angiosperm phylogeny using conserved nuclear genes and estimates of early divergence times. Nat Commun 5:1-12. 